\title{
KAJIAN TEORI MATEMATIKA EVERYONE IS A TEACHER HERE DAN PENDEKATAN QUANTUM TEACHING
}

\author{
Jade Rehulina Muntuan \\ Program Studi Pendidikan Matematika \\ FKIP Universitas Advent Indonesia \\ jade.muntuan@gmail.com
}

\begin{abstract}
Abstrak: Matematika merupakan salah satu mata pelajaran yang dipelajari di semua jenjang pendidikan. Hal tersebut dikarenakan matematika digunakan dan dibutuhkan dalam setiap aspek kegiatan manusia sehari-hari. Salah satu kemampuan yang harus dimiliki siswa adalah kemmampuan pemecahan masalah. Fakta yang ada di Indonesia menunjukkan bahwa kemampuan pemecahan masalah matematis siswa baik di tingkat pendidikan menengah maupun pendidikan tinggi masih belum tinggi. Dari penelitian terdahulu melaporkan bahwa hanya $35 \%$ siswa yang memiliki kemampuan memecahkan masalah, $25 \%$ siswa yang dapat merancang rencana penyelesaian dan $20 \%$ siswa yang memiliki kemampuan untuk meyelesaikan masalah. Sisanya $20 \%$ adalah siswa yang memiliki kemampuan melihat kembali langkah penyelesaian. Melihat laporan-laporan penelitian di atas, maka guru diharapkan memilih strategi yang tepat untuk digunakan dalam melaksanakan proses pembelajaran di kelas agar tujuan yang telah dituliskan dalam rencana pengajaran dapat tercapai. Model pembelajaran Everyone is a Teacher Here (ETH) adalah salah satu alternatif pembelajaran untuk meningkatkan kemampuan pemecahan masalah matematis siswa. Model Pembelajaran ETH adalah pembelajaran yang memberikan kesempatan kepada semua muridnya untuk bertindak sebagai "pengajar" terhadap teman sebayanya atau dalam kata lain "tutor sebaya". Alternatif pembelajaran lain yang dapat digunakan untuk meningkatkan kemampuan pemecahan masalah matematis siswa adalah pendekatan pembelajaran Quantum Teaching. Pendekatan Quantum Teaching dapat memberikan murid pembelajaran yang meriah yang merangsang stimulus otak siswa sehingga pembelajaran dapat berjalan dengan maksimal. Pendekatan Quantum Teaching ini mempunyai kerangka kegiatan berupa Tumbuhkan, Alami, Namai, Demontrasi, Ulangi, dan Rayakan.
\end{abstract}

Kata Kunci: Pemecahan Masalah Matematis, Everyone is A Teacher, Pendekatan Quantum Teaching

Abstract: Mathematics is one of the subjects which is learned at all levels of education. It happens because mathematics is used and needed in every aspect human activity. One of the abilities students must possess is the ability to solve problems. Facts in Indonesia show that students' mathematical problem-solving abilities at both secondary and tertiary education levels are still not high. From previous studies reported that only $35 \%$ of students had problemsolving skills, $25 \%$ of students were able to design completion plans and $20 \%$ of students had the ability to solve problems. The remaining $20 \%$ are students who have the ability to look back at the completion steps. Looking at the research reports above, the teachers are expected to choose the right strategy to be used in carrying out the learning process in the classroom so that the goals that have been written in the teaching plan can be achieved. A learning model called "Everyone is a Teacher Here (ETH)" is an alternative learning to improve students' mathematical problem solving abilities. The ETH Learning Model provides opportunities for all students to act as "instructors" to their peers or in other words "peer tutors". Another alternative learning that can be used to improve students' mathematical problem solving skills is the Quantum Teaching learning approach. The Quantum Teaching Approach can give students an active learning that stimulates the student's brain so that learning can run optimally. This Quantum Teaching Approach has an activity framework in the form of Grow, Experience, Name, Demonstrate, Repeat, and Celebrate. 
Keywords: Problem Solving skill, Everyone is A Teacher, Quantum Teaching Approach

\section{PENDAHULUAN}

Matematika merupakan salah satu mata pelajaran yang dipelajari di semua jenjang pendidikan. Hal ini dikarenakan matematika digunakan dan dibutuhkan dalam setiap aspek kegiatan manusia sehari-hari (Riyadi, 2011). Matematika juga diperlukan untuk menunjang dan mengembangkan ilmu-ilmu lainnya untuk bersosialisasi dalam masyarakat (Arifin, 2014). Dan juga Hudoyo (Miksalmina, 2013) menyatakan bahwa matematika juga berperan 60\% sampai dengan $80 \%$ dalam memajukan suatu negara.

Peraturan Menteri Pendidikan Nasional No.22 tahun 2006 menyatakan tujuan mata pelajaran matematika untuk semua jenjang pendidikan dasar dan menengah adalah agar siswa mampu: (1) Memahami, menjelaskan dan mengaplikasikan konsep matematika secara akurat dalam pemecahan masalah, (2) Menggunakan penalaran pada pola dan sifat serta mampu menjelaskan gagasan pernyataan matematika; (3) Memecahkan masalah yang meliputi kemampuan memahami masalah, merancang model matematika, menyelesaikan model, dan menafsirkan solusi yang diperoleh; (4) Mengkomunikasikan gagasan dengan simbol, tabel, diagram, atau media lain untuk memperjelas masalah; dan (5) Memiliki sikap menghargai kegunaan matematika dalam kehidupan. Wena (2010) juga menyatakan bahwa kemampuan pemecahan masalah adalah ketika siswa mampu untuk menyelesaikan soal-soal non rutin pada bidang matematika. Hal ini sejalan dengan NCTM (2000) yaitu memecahkan masalah adalah suatu tujuan dalam belajar matematika dan juga merupakan alat untuk melaksanakan pembelajaran itu sendiri. Dengan demikian kemampuan pemecahan masalah matematis sangat penting dimiliki oleh siswa. Ketika siswa merasa kesulitan dalam memecahkan soal maka akan terjadi konflik kognitif di dalam dirinya. Hal ini akan membuat cara berpikir dan cara memahami suatu masalah dari siswa tersebut berkembang serta dapat meningkatkan rasa percaya diri siswa melalui jawaban yang telah ia temukan (Yudianto, 2015; Lim, 2006).

Fakta yang ada di Indonesia menunjukkan bahwa kemampuan pemecahan masalah matematis siswa baik di tingkat pendidikan menengah maupun pendidikan tinggi masih belum tinggi (Shodikin, 2015). Penelitian yang telah dilakukan oleh Astuti (2016) pada siswa XI TKJ SMK Muhammadiyah, Khasanah (2016) pada siswa VIII SMP Muhammadiyah 7 Surakarta dan Prihastuti dkk (2013) pada siswa kelas VII SMP Bumi Khatulistiwa mendapati bahwa kemampuan pemecahan masalah matematis siswa masih rendah. Secara lebih spesifik, Khasanah (2016) melaporkan bahwa hanya 35\% siswa yang memiliki kemampuan memecahkan masalah, $25 \%$ siswa yang dapat merancang rencana penyelesaian dan $20 \%$ siswa 
yang memiliki kemampuan untuk meyelesaikan masalah. Sisanya $20 \%$ adalah siswa yang memiliki kemampuan melihat kembali langkah penyelesaian.

Selanjutnya Hayati (2017) menyatakan bahwa faktor-faktor yang menjadi penyebab rendahnya kemampuan pemecahan masalah matematis siswa di SMK Prawira Marta Kartasura adalah lingkungan belajar yang kurang kondusif, kurangnya motivasi siswa dan juga cara guru menyampaikan palajaran kurang bervariasi. Sejalan dengan hal tersebut Tarudin (2012) melaporkan bahwa masalah yang terjadi ketika pembelajaran sedang berjalan adalah siswa cenderung pasif dan guru lebih banyak berperan di dalam kelas. Hal lainnya yang menjadi faktor rendahnya kemampuan pemecahan masalah matematis siswa adalah siswa kurang terbiasa untuk menyelesaikan soal-soal pemecahan masalah atau soal-soal non rutin (Mulyati, 2016). Selanjutnya, sifat dari pelajaran matematika yang memiliki obyek abstrak mengakibatkan siswa kesulitan untuk memecahkan masalah dan menuntut guru untuk menuntun siswa untuk memecahkan masalah matematika dengan cara yang lebih mudah dan menyenangkan (Widiyaningsih, 2013).

Melihat laporan-laporan penelitian di atas, maka guru diharapkan memilih strategi yang tepat untuk digunakan dalam melaksanakan proses pembelajaran di kelas agar tujuan yang telah dituliskan dalam rencana pengajaran dapat tercapai. Model pembelajaran Everyone is a Teacher Here (ETH) adalah salah satu alternatif pembelajaran untuk meningkatkan kemampuan pemecahan masalah matematis siswa. Model Pembelajaran ETH adalah pembelajaran yang memberikan kesempatan kepada semua muridnya untuk bertindak sebagai "pengajar" terhadap teman sebayanya atau dalam kata lain "tutor sebaya". Dari model pembelajaran ETH hasil belajar siswa akan lebih meningkat dan model pembelajaran yang di ajarkan guru akan lebih bervariasi (Musnaeni, 2016; Hartini, 2012). Siswa tidak akan pasif dengan maju ke depan untuk mempresentasikan jawabannya di depan kelas (Sulaiman, 2016). Lingkungan belajar yang tercipta pun menjadi konduktif dengan adanya kegiatan menulis dan menjawab pertanyaan tentang pelajaran yang bersangkutan sehingga lebih mendukung proses belajar mengajar tersebut menjadi lebih efektif (Zuliani dkk, 2015). Dengan diberikan tanggung jawab kepada siswa untuk menulis dan menjawab pertanyaan dapat memotivasi siswa untuk berpikir dan bekerja keras atas inisiatif sendiri sehingga siswa secara individual akan lebih berperan di dalam kelas (Zulkarnain dkk, 2015)

Alternatif pembelajaran lain yang dapat digunakan untuk meningkatkan kemampuan pemecahan masalah matematis siswa adalah pendekatan pembelajaran Quantum Teaching. Pendekatan Quantum Teaching dapat memberikan murid pembelajaran yang meriah yang merangsang stimulus otak siswa sehingga pembelajaran dapat berjalan dengan maksimal 
(Widiyaningsih, 2013). Pendekatan Quantum Teaching ini mempunyai kerangka kegiatan berupa TANDUR (Tumbuhkan, Alami, Namai, Demontrasi, Ulangi, dan Rayakan) yang pembelajarannya mengharuskan siswa untuk aktif dalam pembelajaran. Asas utama dari Pendekatan Quantum Teaching ini adalah: "bawalah dunia mereka ke dunia kita dan antarkan dunia kita ke dunia mereka." (Deporter, 2000). Dengan pendekatan Quantum Teaching siswa merasa senang selama proses pembelajaran yang menghasilkan peningkatan dalam hasil belajar mereka (Sari dkk, 2013). Siswa menjadi lebih aktif dalam mengungkapkan pendapat, berdiskusi dan mengerjakan tugas dikarenakan kondisi lingkungan kelas yang menarik dan tidak membuat siswa jenuh (Yanuarti dkk, 2016). Dengan bantuan penamaan membantu siswa agar lebih mudah untuk mengingat (Yosefa, 2013). Guru menjadi lebih kreatif dalam membuat susasana kelas lebih menyenangkan untuk melaksanakan pembelajaran (Rubiherlan, 2016).

\section{KEMAMPUAN PEMECAHAN MASALAH MATEMATIS}

Masalah matematika didefinisikan sebagai situasi yang memiliki tujuan yang jelas tetapi berhadapan dengan halangan akibat kurangnya algoritma yang diketahui untuk menguraikannya agar memperoleh sebuah solusi (Turmudi, 2008). Siagian dalam Mahira (2012) berpendapat bahwa masalah adalah suatu stimulus yang menuntut suatu respon karena terjadi perubahan di luar dugaan orang tersebut. Dengan menghadapi masalah maka manusia akan dapat memenuhi segala kebutuhan hidupnya.

Terdapat berbagai macam masalah yang ada di kehidupan sehari-hari. Dalam dunia pendidikan, siswa dihadapkan dengan soal-soal non rutin yang berkaitan dengan kehidupan sehari-hari. Soal tersebut akan menjadi masalah bagi siswa tersebut apabila siswa kurang memahami soal tersebut dan sulit untuk menyelesaikannya (Hughes dkk, 2012). Menurut Mawaddah (2015), pemecahan masalah adalah suatu proses berpikir sebagai upaya dalam menemukan suatu masalah dan memecahkannya berdasarkan informasi yang dikumpulkan dari berbagai sumber sehingga dapat diambil suatu kesimpulan yang tepat yang diikuti dengan pemahaman siswa. Noor (2014) menjelaskan bahwa dalam belajar memecahkan masalah, siswa dihadapkan pada berbagai permasalahan kehidupan sehari-hari yang akan membuatnya berusaha untuk menggunakan serta menghubungkan pengetahuan-pengetahuan yang telah dimilikinya. Hal-hal tersebut sesuai dengan yang diungkapkan oleh Polya (1973) mengemukakan bahwa pemecahan suatu masalah adalah menemukan makna yang dicari sampai akhirnya dapat dipahami dengan jelas. Kemampuan pemecahan masalah matematika dalam penelitian ini adalah kemampuan siswa dalam menyelesaikan soal matematika 
berdasarkan langkah-langkah Polya. Adapun langkah pemecahan masalah menurut Polya (1973) yaitu:

1. Memahami masalah (understanding the problem)

Siswa harus membaca soal dengan seksama terlebih dahulu hingga mengerti permasalahan dari soal tersebut. Jika siswa dapat memahami soal tersebut maka siswa akan dapat merumuskan apa yang diketahui, apa yang ditanyakan, serta syarat apa saja yang dibutuhkan dalam menyelesaikan soal.

2. Merancang rencana penyelesaian (devising a plan)

Siswa menyusun rancangan penyelesaian serta menemukan pola dari soal berdasarkan pengetahuan yang telah ia dapatkan.

3. Melaksanakan rencana penyelesaian (carrying out the plan)

Pada tahap ini siswa menjalankan rancangan yang telah dibuat dan menyelesaikan soal yang telah diberikan.

4. Melihat kembali langkah penyelesaian (looking back).

Siswa dapat mengecek jawaban yang sudah didapatkan dengan menguji hasil kerja siswa tersebut ataupun mengerjakan soal tersebut sekali lagi menggunakan cara yang lain.

\section{MODEL PEMBELAJARAN TIPE EVERYONE IS A TEACHER HERE (ETH)}

Model pembelajaran ETH mampu memberi kesempatan kepada setiap siswa untuk berperan sebagai guru bagi kawan-kawannya. Dengan metode ini, siswa yang selama ini tidak mau terlibat akan ikut serta dalam pembelajaran secara aktif. Model pembelajaran ETH ini adalah pengembangan dari model pembelajaran Peer Tutoring. McAllister (1990) menyatakan bahwa William Towle, seorang guru di Boston telah menuliskan langkah-langkah pembelajaran dari Peer Tutoring sejak pertengahan abad ke-19. Model pembelajaran ETH ini juga merupakan salah satu dari tiga belas model pembelajaran yang dikembangkan oleh dosendosen Fakultas Tarbiyah IAIN Jakarta yang telah di uji cobakan di Madrasah Terpadu Jakarta (Adinugroho, 2009).

Model ini dapat diterapkan sesuai dengan materi yang diajarkan, tujuannya untuk menghilangkan kejenuhan siswa dalam belajar (Said dkk, 2015). Menurut Edriati dkk (2009) model pembelajaran ini dapat membantu siswa yang kurang berani untuk bertanya dengan membuat pertanyaan pada kartu-kartu indeks. Laporan-laporan penelitian terdahulu (Musnaeni, 2016; Suparman, 2015; Atikasari, 2014; Kusrini dkk, 2013; Mustika, 2013) menjelaskan bahwa model pembelajaran tipe ETH memiliki langkah-langkah sebagai berikut: 
1. Mengumpulkan informasi

Pada langkah ini, informasi diperoleh siswa dari penjelasan guru tentang materi baru dengan metode ceramah.

2. Membuat pertanyaan

Untuk mengetahui sejauh mana respon peserta didik terhadap materi pelajaran siswa diberikan kertas untuk menulis pertanyaan tentang materi yang baru dipelajari.

3. Mempresentasikan dan menjawab

Pada tahap ini, untuk membangkitkan motivasi siswa agar lebih aktif di kelas para siswa akan menjawab dan mempresentasikan jawaban dari pertanyaan yang ada pada kertas yang sudah didapatkan secara acak.

4. Menanggapi atau mengkonfirmasi

Pada tahap ini, siswa yang hanya mendengar presentasi temannya akan memberi pertanyaan ataupun sanggahan.

Kelebihan dari model pembelajaran ETH membuat siswa lebih percaya diri untuk mempresentasikan hasil kerjanya dengan cara mengajar temannya dan dapat dengan lapang hati menerima masukan dari teman sebayanya (Kusrini dkk, 2014; Mustika, 2013). Dengan melakukan proses pembelajaran ini maka siswa akan termotivasi untuk belajar dengan baik. Kekurangan dari model pembelajaran ini adalah sulitnya untuk menumbihkan motivasi siswa agar mau untuk mengajar siswa lain dan juga kurangnya waktu untuk menghabiskan semua pertanyaan pada kelas yang memiliki jumlah siswa yang banyak pada kelas itu. (Syahruddin, 2018; Musnaeni dkk, 2016).

\section{PENDEKATAN QUANTUM TEACHING}

Riadi (2012) menyatakan bahwa guru berupaya agar dapat membuat strategi pembelajaran yang tidak mengharuskan siswa menghafal tetapi strategi yang dapat meningkatkan pemahaman siswa itu sendiri, salah satunya dengan menerapkan pembelajaran Quantum Teaching. Pada tahun 1982, DePorter mengembangkan ide tentang pembelajaran yang berpusat pada pengembangan potensi diri siswa di Super Camp di Amerika Serikat. Beliau belajar dari Dr Georgi Lozanov, pendidik asal Bulgaria, yang bereksperimen dengan suggestology atau suggestopedia yang memiliki prinsip bahwa motivasi dan peningkatan pembelajaran dapat dipengaruhi oleh sugesti (DePorter, 2004). Teori untuk metode pembelajaran ini antara lain adalah teori otak kanan dan kiri, teori Triune, pilihan modalitas (visual, auditorial dan kinestik) serta pendidikan holistik (Ridho, 2006). Pendekatan ini memiliki asas utama yaitu: "Bawalah dunia mereka ke dunia kita, dan antarkan dunia kita ke 
dunia mereka”. Hal ini menunjukkan bahwa proses pembelajaran ini menyediakan strategi untuk meningkatkan proses belajar mengajar menjadi menyenangkan sehingga siswa dapat belajar bagaimana menciptakan hubungan yang baik ketika dalam proses belajar (DePorter, 2000).

Pembelajaran ini mencakup petunjuk untuk menciptakan siswa yang aktif di kelas dan lingkungan belajar yang efektif (Ngalimun, 2017). Lingkungan belajar yang efektif yang dimaksud adalah sebagai berikut

1. Lingkungan sekeliling

Lingkungan adalah salah satu faktor kondisional belajar yang mempengaruhi tingkah laku individu (Hamalik, 2004). Pembelajaran ini mengubah lingkungan belajar siswa dengan memberikan poster ikon tentang materi yang akan dipelajari agar memperkuat ingatan siswa. (Deporter, 2000; Santrock, 2004).

2. Alat bantu

Alat bantu atau alat praga yang digunakan dapat mewakili gagasan dari pembelajaran tersebut dan digunakan sesuai kebutuhannya. Alat bantu dapat membantu siswa agar dapat lebih memahami pembelajaran tersebut (Saputra, 2009; Rusyan dkk,1992).

3. Pengaturan bangku

Bangku siswa disusun untuk mendukung tujuan pembelajaran sehingga dapat membantu meningkatkan konsentrasi siswa. Bangku-bangku siswa juga disusun sesuai dengan kondisi dan keadaan kelas agar siswa tetap merasa nyaman ketika proses belajar mengajar di kelas berlangsung (Damayanti, 2016).

4. Tumbuhan

Tumbuhan dapat menambah estetika dalam lingkungan belajar kelas yang dapat membuat siswa lebih semangat belajar. Tumbuhan juga merupakan salah satu media sederhana yang dapat memaksimalkan panca indra siswa dalam belajar karena menghasilkan oksigen yang dapat membuat otak semakin berkembang (Alam, 2012)

5. Musik

Musik klasik dan musik instrumental juga dapat dijadikan sebagai media pembelajaran sehingga pembelajaran menjadi menyenangkan, rileks tetapi tetap mampu untuk berpikir, serta dapat membantu mempertajam ingatan siswa. (Sanjaya, 2010; Damayanti, 2016)

Kerangka pembelajaran Quantum Teaching menurut DePorter (2000), Solikin (2014) dan Widiyaningsih (2013) adalah sebagai berikut:

1. Tumbuhkan (Grow)

Tumbuhkan minat belajar siswa dengan memberikan motivasi melalui cerita-cerita serta dengan cara mengubah lingkungan kelas agar lebih menarik untuk melaksanakan pembelajaran (Damayanti, 2016). 
2. Alami (Experiencing)

Materi pelajaran yang akan dipelajari dihubungkan dengan kehidupan sehari-hari agar dapat mudah dimengerti siswa (Wlodkowski dkk, 2004; Santrock, 2004).

3. Namai (Naming)

Pelajaran yang diterima oleh siswa akan disertai dengan nama maupun kata kunci yang akan membantu siswa untuk mendapatkan informasi dari pembelajaran tersebut (Joyce dkk, 2009).

4. Demonstrasikan (Demonstrate)

Siswa diberikan kesempatan untuk menyatakan pelajaran yang baru ia dapatkan melalui presentasi. Siswa tersebut bisa mengembangkan presentasinya dengan menghubungkan pelajaran yang sedang ia pelajari dengan pelajaran yang lain. Siswa dapat meningkatkan rasa percaya diri dan mengaplikasikan tingkat kecakapannya dengan pelajaran (Silberman, 2014; Hughes dkk, 2012).

5. Ulangi (Repeat)

Guru mengulangi hal-hal yang kurang jelas bagi siswa. Siswa dapat dengan mudah memahami dan mengetahui pelajaran tersebut. Guru memberikan kesempatan bagi siswa untuk mengajarkan pengetahuan kepada siswa yang lain (Hughes dkk, 2012).

6. Rayakan (Celebrate)

Mengadakan perayaan bagi siswa akan mendorong siswa memperkuat rasa tanggung jawab dan mengamati proses belajar sendiri. Perayaan tersebut akan mengajarkan siswa mengenai motivasi belajar, kesuksesan, langkah menuju kemenangan. Pujian yang didapatkan akan mendorong siswa agar tetap dalam keadaan bersemangat dalam proses belajar mengajar (Wlodkowski dkk, 2004).

Kelebihan dari pembelajaran ini adalah pembelajaran ini akan menjadi pembelajaran yang menyenangkan dan nyaman bagi siswa sehingga siswa dapat menjadi lebih kreatif, percaya diri dan mau bekerja sama (Mulyaningsih dkk, 2017). Kekurangan dari pembelajaran ini adalah kurangnya kreativitas guru dalam menciptakan suasana kelas yang menyenangkan tetapi tetap fokus pada pembelajaran. Dan juga karena suasana kelas yang meriah dan menyenangkan dapat mengganggu kegiatan belajar mengajar di kelas lain (Saiman dkk, 2008; Rifai dkk, 2012)

\section{MODEL EVERYONE IS A TEACHER HERE DAN PENDEKATAN QUANTUM TEACHING}

Pada bagian ini akan dijelaskan langkah-langkah pembelajaran apabila model pembelajaran ETH digabung dengan pendekatan Quantum Teaching (Musnaeni, 2016; Suparman, 2015; Atikasari, 2014; Kusrini, 2013; Mustika, 2013; Damayanti, 2016; 
Wlodkowski dkk, 2004; Hughes dkk, 2012; Silberman, 2014; Joyce dkk, 2009; Santrock, 2004).

Langkah-langkah pembelajaran ETH dan Quantum Teaching adalah sebagai berikut:

1. Memberi motivasi kepada siswa

Mengubah lingkungan kelas dengan cara menambah poster-poster ahli-ahli matematika, hiasan kelas dan bunga di dalam kelas. Dan juga akan diputar musik klasik selama pembelajaran kelas berlangsung agar siswa lebih termotivasi untuk semangat belajar (Grow).

2. Mengumpulkan informasi

Pada langkah ini, informasi diperoleh siswa dari penjelasan guru tentang materi baru dengan metode ceramah. Penjelasan dari guru berbantuan alat peraga dan dihubungkan dengan kehidupan sehari-hari agar siswa dapat lebih mudah untuk mengerti dan dapat termotivasi belajar lebih baik lagi (Experiencing).

3. Membuat pertanyaan

Untuk mengetahui sejauh mana respon peserta didik terhadap materi pelajaran siswa diberikan kertas berwarna-warni untuk menulis pertanyaan tentang materi yang baru dipelajari. Siswa menulis kata kunci dari pertanyaan yang dibuat agar siswa lain yang menerima pertanyaan tersebut dapat lebih mudah untuk mengerti dan menyelesaikan soal tersebut (Naming).

4. Mempresentasikan dan menjawab

Pada tahap ini, para siswa akan menjawab dan mempresentasikan jawaban dari pertanyaan yang ada pada kertas yang sudah siswa dapatkan secara acak didepan kelas dengan menggunakan spidol berwarna-warni ataupun berbantuan alat praga (Demonstrate).

5. Menanggapi atau mengkonfirmasi

Pada tahap ini, siswa yang hanya mendengar peresentasi temannya akan memberi pertanyaan ataupun sanggahan. Pertanyaan tersebut akan dijelaskan kembali oleh guru sehingga tidak terjadi kesalahan dalam pemahaman konsep (Repeat).

6. Perayaan

Setelah selesai pengulangan pembahasan soal, siswa yang sudah melakukan presentasi di depan kelas akan diberikan apresiasi dalam bentuk tepuk tangan dan pujian oleh temanteman sekelasnya dan diberikan poin tambahan oleh guru (Celebrate).

\section{DAFTAR PUSTAKA}

Adinugroho, S. (2009). Pembelajaran Everyone is a Teacher Here.[Online]. Avalaible at https://nazwadzulfa.wordpress.com/2009/09/30/pembelajaran-every-one-is-a-teacher-here/.[3 Juli 2018]. 
Alam, S. (2012). Efektivitas Penggunaan Tanaman Sebagai Media Pembelajaran Biologi dalam Pokok Bahasan Struktur Tumbuhan Siswa Kelas VII MTs. Syekh Yusuf Sungguminasa Kabupaten Gowa. Makasar: Universitas Islam Negeri UIN Alauddin (Skripsi).

Arifin, A. T., Kartono, K., \& Sutarto Hery. (2014). Keefektifan Strategi Pembelajaran React pada Kemampuan Siswa Kelas VII. Jurnal Matematika Kreatif-Inovatif, 5(1), 91-98.

Astuti, D. (2016). Meningkatkan Kemampuan Pemecahan Masalah Matematis Melalui Model Pembelajaran Student Teams Achievment Development (STAD). Yogyakarta: Universitas Ahmad Dahlan Yogyakarta. (Skripsi).

Atikasari. (2014). Penerapan Model Everyone is a Teacher Here dalam Pembelajaran IPS Kelas IV Semester II di MI Negeri Jambusari Cilacap Tahun Pelajaran 2013/2014. Purwokerto: Sekolah Tinggi Agama Islam Negeri Purwokerto. (Skripsi).

Damayanti. (2016). Sukses Menjadi Guru Humoris dan Idola yang Akan Dikenang Sepanjang Masa. Yogyakarta: Araska.

DePorter, B., \& Hernacki, M. (2004). Quantum Learning: Membiasakan Belajar Nyaman dan Menyenangkan. Bandung: Kaifa.

DePorter, B., Reardon, M., \& Singer-Nourie, S. (2000). Quantum Teaching: Mempraktekkan Quantum Learning di Ruang-Ruang Kelas. Bandung: Kaifa.

Edriati, S., Suryani, M., \& Putri, W. R. (2016). Upaya Peningkatan Pemahaman Ruang Siswa SMP Melalui Strategi Everyone is a Teacher Here. Jurnal Pelangi, 9(1), 52-60.

Hamalik, O. (2004). Proses Belajar Mengajar. Jakarta: Bumi Aksara.

Hartini, H. (2012). Upaya Meningkatkan Keaktifan Peserta Didik melalui Perpaduan Model Pembelajaran Everyone is a Teacher Here dan Team Quiz dalam pembelajaran Fiqih Kelas V Semester Ganjil Materi Pokok Makanan dan Minuman yang Halal dan yang Haram di MI Miftahul Huda. IAIN Walisongo. (Skripsi)

Hayati, T. N. (2017). Peningkatan Kemampuan Pemecahan Masalah dan Hasil Belajar Matematika SIswa melalui Model Pembelajaran Problem Posing (PTK Siswa Kelas X AP 2 SMK Prawira Marta Kartasura Tahun Ajaran 2016/2017). Surakarta: Universitas Muhammaddiyah Surakarta. (Skripsi).

Hughes, A., \& Hughes, E. H. (2012). Learning \& Teaching, Pengantar Psikologi Pembelajaran Modern. Yogyakarta: Nuansa.

Joyce, B., Weil, M., \& Calhoun, E. (2009). Models of Teaching Edisi Kedelapan. Yogyakarta: Pustaka Pelajar.

Khasanah, N. U. (2016). Peningkatan Kemampuan Pemecahan Masalah Matematika melalui Strategi Realistic Mathematics Education Berbasis Group Investigation pada Kelas VIII SMP Muhammadiyah 7 Surakarta Tahun 2015/2016. Surakarta: Universitas Muhammadiyah Surakarta. (Skripsi).

Kusrini, E. D., \& Nurhidayah, D. A. (2014). Penerapan Model Pembelajaran Everyone Is A Teacher Here Dalam Upaya Meningkatkan Aktivitas Dan Hasil Belajar Matematika Siswa Kelas VIIA MTs Ma'arif Al Ishlah Bungkal Tahun Pelajaran 2013/2014. [Online]. Available at eprints.umpo.ac.id/296/1/ARTIKEL.pdf [12 Agustus 2018]

Lim, K. (2006). Characterizing Students' Thingking: Algebra inequalities and equations: In S. Alatorre, J. L. COrtina, M. Saiz \& A Mendez (Eds.) . Proc. 28th Annual Meeting of the North American Chapter of the Int. Group for the Psychology of Mathematics Education, 102-109. 
Mahira. (2012). Penerapan Model Project Based Learning untuk Meningkatkan Kemampuan Memecahan Masalah Siswa pada Konsep Pencemaran Lingkungan. Bandung: Universitas Pendidikan Indonesia. (Skripsi).

Mawaddah, S., \& Anisah, H. (2015). Kemampuan Pemecahan Masalah Matematis Siswa pada Pembelajaran Matematika dengan Model Pembelajaran Generatif di SMP. Jurnal Pendidikan Matematika, 3(2), 166-175.

McAllister, E. (1990). Peer Teaching and Colaborative Learning in the Language Arts. United States: EDINFO Press.

Miksalmina. (2013). Penguasaan Siswa pada Materi Trigonometri di MAN Darussalam Aceh Besar. Jurnal Visipena, 4(2), 101-110.

Mulyati, Tita. (2016). Kemampuan Pemecahan Masalah Matematis Siswa Sekolah Dasar. EduHumaniora Jurnal Pendidikan Dasar, 3(2), 1-15

Available at http://ejournal.upi.edu/index.php/eduhumaniora/article/view/2807

Musnaeni, \& Nasaruddin. (2016). Pembelajaran Everyone is a Teacher Here dan Pengaruhnya terhadap hasil Belajar Matematika Siswa. Jurnal Pendidikan Matematika dan Ilmu Pengetahuan Alam, $4(1), 15-28$.

Mustika, I. (2013). Peningkatan Keaktifan Belajar dalam Pembelajaran Model Everyone is a Teacher Here dalam Materi Dakwah Nabi Muhammad SAW di Kelas IV MI Darus Sa'adah Tlogosari Kulon Semarang 2013/2014. Semarang: Institut Agama Islam Negeri Walisongo.

NCTM. (2000). Priciples and Standards for School Mathematics. USA: NCTM.

Ngalimun. (2017). Strategi Pembelajaran di Lengkapi dengan 65 Model Pembelajaran . Yogyakarta: Parama Ilmu .

Noor, A. J., \& Norlaila. (2014). Kemampuan Pemecahan Masalah Matematika dalam Pembelajaran Maatematika menggunakan Cooperative Script. Jurnal Pendidikan Matematika, 2(3), 250-259.

Permendiknas. (2006). Permendiknas No. 22 Tentang Standar Isi Sekolah Menengah Pertama. Jakarta: Depdiknas.

Polya, G. (1973). How to Solve It. New York: Doubleday.

Prihastuti, W. S., Hudiono, B., \& Mirza, A. (2013). Pemecahan Masalah Matematis Siswa di tinjau dari Tingkat Kemampuan Dasar Matematika. Jurnal Pendidikan dan Pembelajaran, 2(12), 1-16.

Riadi, M. (2012, Oktober 11). Model Pembelajaran Quantum Teaching. [Online]. Available at http://www.kajianpustaka.com/2012/10/model-pembelajaran-quantum-teaching.html?m=1.

[11 Juni 2018]

Rifai, A., Suhartono, \& Ngatman. (2012). Penerapan Pendekatan Quantum Teaching dalam Pembelajaran IPA di Kelas V SDN 2 Jogomertan. Kalam Cendekia PGSD Kebumen, 1(1).

Riyadi, A. (2011). Meningkatkan Hasil Belajar Matematika Melalui Pendekatan Realistic Mathematic Education pada Siswa Kelas IV SDN I Gununggajah Kecamatan Bayat Kabupaten Klaten Tahun ajaran 2011/2012. Purwakarta: Universitas Muhammadiyah Surakarta. (Skripsi).

Rubiherlan, Y. (2016). Pembelajaran Quantum Teaching untuk Meningkatkan Kreativitas Belajar Siswa Pada pelajaran IPS. [Online]. Available at https://yususfrubiherlan.blogspot.com/2011/05/pembelajaran-quantum-teachinguntuk.html?m=1. [11 Juni 2018]

Rusyan, A. T., Kusnidar, A., \& Arifin, Z. (1992). Pendekatan dalam Proses Belajar Mengajar. Bandung: PT Remaja Rosdakarya. 
Said, M. A., Nirmayanti, \& Nurlina. (2015). Penerapan Pembelajaran Aktif Tipe Everyone is a Teacher Here (ETH) untuk Meningkatkan Hasil Belajar Fisika Peserta Didik Kelas Xa SMA Al Bayan Makassar. Prosiding Seminar Nasional Fisika (E-Journal). 4

Saija, L. M., (2010). Pembelajaran Berbasis Masalah dengan Model Kooperatif MURDER untuk Meningkatkan Kemampuan Pemecahan Masalah Matematis Siswa SMA. Bandung: Universitas Pendidikan Indonesia. (Tesis).

Saiman, M., \& Slameto. (2008). Model Pembelajaran Quantum Teaching untuk Meningkatkan Hasil Belajar IPS Kelas V SDS Kalam Kudus Kecamatan Tebing Tinggi, Kabupaten Bengkalis. Jurnal Ilmu-ilmu Sejarah, Budaya dan Sosial, 89-117.

Sanjaya, A. A. (2010). Penggunaan Musik dalam Pembelajaran di Kelas untuk Menciptakan Kerja Otak yang Harmonis. [Online]. Available at https://www.kompasiana.com/alit.adi.sanjaya/penggunaan-musik-dalam-pembelajaran-dikelas-untuk-menciptakan-kerja-otak-yang-harmonis_550055fea33.

Santrock, J. W. (2004). Psikologi Pendidikan Edisi Kedua. Jakarta: Prenadamedia Group.

Saputra, D. K. (2009). Media (alat bantu) Pembelajaran. [Online]. Available at dwikurniasaputro.worpress.com/2009/12/04/114/amp.

Sari, R. S., Lufri, \& Anhar, A. (2013). Pengembangan Modul Biologi Berorientasi Quantum Teaching dilengkapi Peta Pikiran untuk Siswa Kelas XI SMA. Kolaboratif, 1(2), 9-18.

Shodikin, A. (2016). Peningkatan Kemampuan Pemecahan Masalah Siswa melalui Strategi AbduktifDeduktif pada Pembelajaran Matematika. Jurnal Matematika Kreatif Inovatif, 6(2), 101-110.

Silberman, M. (2014). Active Learning, 101 Cara Belajar Siswa Aktif. Bandung: Nuansa Cendekia.

Sulaiman. (2016). Pengaruh Strategi Everyone is a Teacher Here terhaap Hasil Belajar Matemtaika Siswa. Jurnal e-DuMath, 2(1).

Suparman. (2012). Penerapan Pembelajaran Aktif Everyone is a Teacher Here untuk Meningkatkan Keaktifan dan Hasil Belajar Kompetensi Dasar Sistem Pengisian Kelas X SMK Perindustrian Yogyakarta 2011/2012. Yogyakarta: Universitas Negeri Yogyakarta. (Skripsi).

Syahruddin, S. (2018). Pengaruh Strategi Everyone Is a Teacher Here(ETH), Contextual Teaching and Learning (CTL), dan Crossword Puzzle (CWP) serta Motivasi Belajar Terhadap Hasil Belajar Siswa pada Mata Pelajaran Bahasa Arab di MTs Darul Falah Aek Songsongan. Analytica Islamica, 7(1), 60-75.

Tim Pengembang Ilmu Pendidikan FIP-UPI. (2009). Ilmu \& Aplikasi Pendidikan Bagian 1: Ilmu Pendidikan Teoritis. Grasindo. [Online] Available at http://books.google.co.id/books?=id=TkqF8C8ffK4C\&dq=intitle:ilmu+peluang\&hI= \&source=gbs_api

Tarudin. (2012). Kemampuan Pemecahan Masalah Matematik antara siswa yang mendapatkan Pembelajaran Tipe Murder dan Tipe Jigsaw. Bandung: Universitas Pendidikan Indonesia (Tesis).

Turmudi. (2008). Pemecahan Masalah Matematika. [Online]. Available at http.//file.upiedu/irektori/FMIPA/JUR.PEND.MATEMATIKA/196101121987031TURMUDI/F20-PEMECAHAN MASALAH MATEMATIKA-1-11-2008.Pdf.

Wena, M. (2010). Strategi Pembelajaran Inovatif Kontemporer. Jakarta: Bumi Aksara.

Widiyaningsih, E., \& Pujiastuti, E. (2013). Keefektifan Pembelajaran Model Quantum Teaching berbantuan Cabri 3D terhaap Kemampuan Pemecahan Masalah. Jurnal Matematika KreatifInovatif, 4(1).

Wlodkowski, R. J., \& Jaynes, J. H. (2004). Hasrat Untuk Belajar. Yogyakarta: Pustaka Pelajar. 
Yanuarti, A., \& Sobandi, A. (2016). Upaya Meningkatkan Hasil Belajar Siswa Melalui Penereapan Model Pembelajaran Quantum Teaching. Jurnal Pendidikan Manajemen Perkantoran, 1(1), 11-18.

Yosefa, B., \& Nurjanah, E. (2013). Pengaruh Metode Pembelajaran Quantum Teaching dengan Menggunakan Mind Mapping terhadap Kemamuan Penalaran Matematis paa Siswa SMP kelas CIII. Jurnal Pengajaran Matematika dan Ilmu Pengetahuan Alam, 18(2), 146-151.

Yudianto, E. (2015). Profil Antisipasi SIswa SMA dalam Memecahkan Masalah Integral. Jurnal Matematika Kreatif-Inovatif. 6

Zuliani, P., Nasir, M., \& Habibati. (2015). Penerapan Model Pembelajaran Everyone is a Teachere Here (ETH) untuk Meningkatkan Aktivitas dan Hasil Belajar Kimia Koloid Siswa Kelas XI IA di SMA Negeri 5 Banda Aceh. Jurnal Ilmiah Mahasiswa Pendidikan Kimia (JIMPK). 2(1). 65-72.

Zulkarnain, Hardianto, \& Jufri. (2015). Pengaruh Model Pembelajaran Kooperatif Tipe Everyone is a Teacher Here (ETH) terhadap Hasil Belajar Siswa Kelas VII MTS Thamrin Yahya. Jurnal Mahasiswa FKIP Universitas Pasir Pengaraian, 1-8. 